\title{
Culture Clash in the Multicultural Classroom: A Case Study From a Newcomer School
}

\author{
Holly Hansen-Thomas ${ }^{1} \&$ SriPadmini Chennapragada ${ }^{1}$ \\ ${ }^{1}$ Department of Teacher Education, Texas Woman's University, Denton, Texas, USA \\ Correspondence: Holly Hansen-Thomas, P. O. Box 425769, Denton, TX 76204, USA. Tel: 940-898-2265. \\ E-mail: hhansenthomas@twu.edu
}

Received: February 24, 2018

Accepted: March 18, 2018 Online Published: March 20, 2018

doi: $10.5539 /$ elt.v11n $4 \mathrm{p} 82$

URL: http://doi.org/10.5539/elt.v11n4p82

\begin{abstract}
This ethnographic case study of a multicultural/multilingual classroom in a newcomer school describes an incident that occurred among new immigrant English Language Learners from widely diverse backgrounds in a secondary classroom in Texas. Increased numbers of immigrant students in U.S. schools have resulted in classrooms with tremendous diversity in terms of language, ethnicity, culture, religion, among other categories. The incident arose as the result of a clash of cultures and lack of knowledge on the part of students. As a result, an explicit focus on culturally responsive teaching is called for, as is training for teachers in multicultural classrooms regarding the specific demographic backgrounds of their students.
\end{abstract}

Keywords: superdiversity, culturally responsive teaching, multicultural classrooms, Newcomers in United States

\section{Introduction}

\subsection{Problem and Purpose of Study}

Classrooms in the U.S. are becoming more and more diverse as regards language, ethnicity, cultural and religious backgrounds. From 1970 to 2015, the United States has had an increase in immigrant population from 9.6 to 43.3 percent (U.S. Census Bureau, 2010). Increased numbers of English Language Learners (ELLs) from a variety of backgrounds have contributed to such diversity (OELA, 2017). New immigrants are a special case of ELLs as they come to school with educational and linguistic gaps. Newcomer programs are special academic programs designed for such new immigrants in U.S. secondary schools with the primary aim of facilitating the transition to American public school and reducing underachievement (Boyson \& Short, 2012). These programs serve students from a wide range of ethnolinguistic backgrounds and can be considered superdiverse academic communities (see Blommaert, 2013 for more on superdiversity).

Certain parts of the U.S. have greater numbers of ELLs than others, and Texas is invariably one of these areas. The Migration Policy Institute (MPI) reports that as of the year 2015, the state of Texas had about 4.4 million immigrants. The context of the case study we describe here is that of a newcomer program, specifically, a newcomer school in a large urban area in Texas.

Previously published research has established the fact that new immigrants in the U.S. face challenges in acculturalization and engagement with peers in the schools where they join (Gándara \& Contreras, 2008). Specialized newcomer programs benefit these students in a variety of ways, such as the following: helping to reduce the burden of students having to immediately succeed in high-stakes testing prior to mastering English language (Short \& Boyson, 2004); aiming to reduce drop outs; promoting students' acculturation to U.S. schools, and incorporating parents in students' educational experience (Short, 1998). According to Friedlander (1991), newcomer programs are designed primarily for late-arrival immigrant students with limited proficiency in English, but many students in newcomer programs also lack age-appropriate education in their home country and familiarity with the American school system. Newcomer schools are host also to refugee children, who come to school with a range of issues running the gamut from low self-esteem to personal trauma - such as that experienced by children in war-torn areas (Friedlander, 1991).

This ethnographic case study of a multicultural/multilingual science classroom in a newcomer school describes an incident that occurred among new immigrant ELLs. The incident arose as a result of a clash of cultures and lack of knowledge on the part of students. As a result, an explicit focus on culturally responsive teaching is called for, as is 
training for newcomer school teachers (and indeed, all teachers in multicultural classes) regarding the specific demographic backgrounds of the students in their classrooms. To organize and eventually analyze the findings from the ethnographic research that was conducted, tenets of culturally responsive teaching were utilized as a theoretical framework (Gay, 2010).

\section{Review of Literature}

Culturally responsive teaching can be defined as a pedagogical method that combines the cultural competence of a teacher with classroom strategies that help culturally and linguistically different students achieve academic success (Gay, 2010). Teaching strategies and lesson planning that incorporate culturally relevant information for students to understand lessons better are two key foundations of culturally responsive teaching. While interacting with students, culturally responsive instructors are empathetic, supportive and flexible in their approach (Shade, Kelby \& Oberg, 1997). That is, “....all practice needs to be culturally responsive in order to be best practice" (Moje \& Hinchman, 2004, p. 321). Being responsive to the needs of students from different cultural backgrounds generates an importance of supporting them in their efforts towards academic success (Ford, 2010). Culturally responsive teaching encompasses the practices of (a) paying close attention to cultural backgrounds of students when applying teaching strategies, (b) being considerate to the restrictions in social communication practices that the students bring with them into the classrooms, (c) creating connections between their existing knowledge and academic goals and (d) exploring possibilities to establish the importance of utilizing their cultural diversity for academic success.

With the evolving demographics in United States, it is important for teachers entering the profession to be prepared to teach in classrooms that are more diverse, than it has been in years past. According to Sadker, Sadker, \& Zittleman (2008), fifty percent of all students in the U.S. will be culturally and linguistically diverse (CLD) by the year 2030. The diversity index of a classroom indicates through a random selection the probability of finding two students from different ethnic groups in a classroom (Parajes \& Urdan, 2005). In 2006, the diversity index for classrooms across the United States stood at 61 percent (the latest available data in this area nationally) (The New York Times, 2015). During the year 2011, the National Center for Education Statistics reported that the school diversity index in the state of Texas was at 63 percent (Asian 4\%, Black 13\%, Hispanic 51\%, White 31\%, others $2 \%$ ). The state teacher diversity index was at 32 percent between white and nonwhite teachers. Considering the growing diversity in American classrooms, it can be well stated that one need not travel abroad to teach in multicultural or multilingual classrooms.

According to Villegas \& Lucas, teachers interested in delivering culturally responsive lessons should be willing to educate themselves about world cultures before they can teach multicultural students (2002). In preparing teachers to work in multicultural classrooms, learning a foreign language can be of great help. It introduces them to the difficulties and anxieties of learning a new language which CLD students often go through in achieving academic success in English-speaking classrooms (Chisholm, 1994). Education delivered in multicultural environments is often considered to be a dynamic process that encompasses participation of personnel who are trained to deliver culturally responsive teaching. This pedagogical approach provides an equal opportunity for students of any race, color, gender or socioeconomic status to learn and compete equally in academic endeavors (Banks \& McGee Banks, 2010). Attitudes of teachers and staff interacting with students in multicultural classrooms have an impact on its climate (Kea, Trent, \& Davis, 2002). Teachers servicing multicultural classrooms have high expectations for all their students irrespective of their cultural origins and also strive to provide feedback that is constructive and supports academic success (Rychly \& Graves, 2012).

A teacher's respect for cultural differences that students bring with them supports the creation of a culturally responsive classroom. Candid discussions about topics that are usually excluded from classroom discussions are encouraged by teachers who employ culturally responsive teaching strategies. On the contrary, teachers who are unaware of the language and environments that their students come from are often unable to estimate a child's competence accurately (Villegas \& Lucas, 2002). Negative stereotypes and inaccurate perceptions about CLD students and their families can lead teachers to overlook a CLD students' performance while evaluating for placement (Huff et al., 2005). Researchers have written about how "aversive racism" impacts the decisions of people practicing it (Dovidio et al., 2002). Curriculum and teaching methods also play a role in the ways in which CLD students are perceived and evaluated. A practice that supports the existence of misconceptions is use of curriculum that is generally passive and sets lower academic goals for students who are perceived to be belonging to culturally deprived, economically disadvantaged and underprivileged backgrounds (Kuykendall, 2004; Rychly $\&$ Graves, 2012). While the intent of such a practice is likely not a negative one, withholding challenging academic experiences for CLD students can be detrimental to a student's growth and success in school. 
The "color blind" approach of teaching in a multicultural classroom is often criticized by researchers as it causes more problems than solves them. A color blind approach in classroom teaching can be explained as teachers who choose not to acknowledge the presence of CLD students and justify the approach by treating every student 'equally'. But this approach creates a disadvantage to the CLD students being serviced as teachers fail to apply the basics of culturally responsive teaching methods in delivering lessons (Howard, 2010). All students, and arguably, especially CLD students, need to have their backgrounds taken into account within the learning process.

\section{Research Methodology}

Ethnographic methods were employed to collect classroom data (Watson-Gegeo, 1997). The first author and researcher spent approximately five weeks observing and researching in a high school chemistry class at a long-established newcomer school called the Newcomer School of America, or NSA (Note 1). She worked with the teacher, Ms. Mayor, and the students, as a participant observer, to learn how Ms. Mayor taught science with ELLs in her class. The researcher followed a unit and observed the students as they worked in pairs and small groups. Videos, audio, photos, and field notes were collected to help understand how NSA teachers interact with their ELLs. Audio was transcribed and video was used to support transcription and to provide visual clues to understand non-verbal language. An analysis of classroom discourse provided insight on cultural differences and interpersonal interactions in the classroom (Cazden, 2001). Triangulation of data sources including field notes, transcripts and video was employed to help shed light on those situated meanings and cultural models (sociocultural practices) (Gee, 2014) used by the ELLs in Ms. Mayor's Chemistry class. Human subjects permissions to conduct this ethnographic research were granted from the Institutional Review Board (IRB) of the university where the authors work.

\subsection{The School}

The Newcomer School of America (NSA), a school dedicated to teaching newcomer ELLs from multiple countries, has been in existence for many years. The NSA serves refugees and recent immigrant students who have had limited (or in some cases, non-existent) schooling of adolescent age. Because all of the teachers at the NSA work with English as a Second Language populations, they were all trained in ESL methods. Moreover, many of the teachers continued their professional development training throughout their tenure at the NSA. Teacher professional development at the NSA deals with issues critical to the changing populations the school serves. These changing populations often reflect political unrest in the world. For example, some years are characterized by large groups of refugees from Somalia; other years, Iraqi teens come in great numbers. Other times, families and communities come by word of mouth. The school serves speakers of Tigrinya from Eritrea, Krio speakers from Sierra Leone, Karenni speakers from Thailand, Chin speakers from Myannmar, among many others. Recently, however, the school had an influx of new families from the Middle East. Because the NSA is located in Texas, a state whose ESL population is majority Spanish speakers (Flores, Batalova, \& Fix, 2012), students from Latin America are a large percentage of the student body. There are many Spanish-speaking students primarily from Mexico and Central America at the school.

Students at the NSA generally spend one year at the school and then transition to their neighborhood school, but will continue to receive ESL support. However, those students with limited or interrupted schooling called SIFE or SLIFE (students with (limited) interrupted formal education), or those with no or low literacy in their home language (DeCapua \& Marshall, 2010) may stay at the NSA for up to two years. The 'graduation,' or school leaving transitions from the NSA to the students' 'home' schools (or those geographically near where they live and where they are zoned to attend) happen several times a year. Thus, students in an NSA classroom will likely not stay in the class together for an entire school year, as is typical in traditional public schools in the U.S. Students may also enter school at the NSA at any point in the academic year. As a result, there is much movement and a lack of consistency in terms of the student body in the classroom.

\subsection{The Teacher, Classroom, and the Students}

Ms. Mayor (Note 2) teaches chemistry to newcomer students at the NSA. At the time of this study, Ms. Mayor had taught for over a decade, and for many of those years at the NSA. Having taken advantage of many professional development opportunities to work with the diverse populations in her classes, Ms. Mayor was well-trained, but nevertheless sometimes demonstrated a self-conscious attitude about her work with her ELLs.

Ms. Mayor's classes are extremely diverse in terms of cultural and linguistic backgrounds. In the 2014-2015 academic year (when the research was conducted), Ms. Mayor's chemistry class consisted of 18 high school students ranging in age from 14-17. Fourteen of the students were Latina/o Spanish speakers from Mexico, Guatemala, Honduras, Nicaragua, and the like (6 males, 8 females). One male student was from China, two siblings (brother and sister) had recently come from Syria, and another girl was from Somalia. The two 
non-Latinas were Muslim and wore hijab (head covering). The Syrian girl wore full hijab, but did not cover her face. Some of the students in the class were close to completion, while others had recently joined the class.

The students (Note 3) on which we focus in this case study are four: two Latino boys, one Syrian boy and the Syrian girl. The boys, Emerson and Guillermo, were from Nicaragua and Guatemala, respectively. They often worked together in class and were good friends. Muscular, stocky, and well-dressed, the two boys favored each other and looked almost like brothers. Wearing bright brand name collared or button down shirts, tight jeans rolled up at the bottom, and sporting short haircuts, the boys sat at the same table throughout the time they were in class together. They were generally polite, and very jocular with each other. At the time of data collection, Emerson was almost near the point in which he would transfer out of the NSA and move to his neighborhood school, as he had passed some of his language proficiency tests. Guillermo, however, had somewhat longer to stay at the NSA. The girl, Diwa, had just immigrated to the U.S. as a refugee with her family. Her brother, Mohammed, was just a bit older than Diwa and very protective of her. He was tall, lanky, and thin, with pursed lips and a pensive face. The siblings were separated in class; Diwa sat with Emerson and Guillermo, and Mohammed sat with other Latina girls at a table at the back of the room.

The unit plan that Ms. Mayor was teaching during the fall term was on atoms and molecules. Specific concepts the students were learning about included the history of chemistry, important chemists, and atomic structure. The students had worked together on this unit for six weeks doing reading activities, model building, writing tasks, and a lot of pair and group work. During this unit, the students were learning about atoms and molecules through the support of scaffolding with tools including sentence strips, models, pictures, and charts. They also discussed the history of chemistry, the important scientists responsible for discovering the field, and toward the end of the unit, even created their own atoms. What happened after class in early November was a surprise that no one was expecting.

\section{Findings: The Incident}

In the fall of 2014, the first author visited the school, as she had for several weeks. On this cool autumn morning, the students were seated at their small group tables with 3-4 students at each table. There were five tables in the class set up almost as a semi-circle, or half-moon shape, facing the teacher and the white board. This day, the students began the day as a whole class activity consisting of a warm up focused on drawing the Bohr model for aluminum. Then, the teacher explained to the students how to do a procedural writing and highlighted terms necessary for inclusion in such a writing including first, second, third, next, last. Then the students moved into their small groups and began the task for the day, which was to choose their own atom to develop, create, and ultimately, build. Each student was responsible for developing their own specific atom first, filling out a teacher created work sheet (see Figure 1), and then they shared in groups. Upon completion of the atom building, they used what they learned about procedural writing and wrote a paragraph on how they built their atom. 


\section{How to Build an Atom: Worksheet}

I. Use vocabulary such as the following:

Atomic Number | Electron | Mass Number | Nucleus | Proton | Energy Level | Neutron
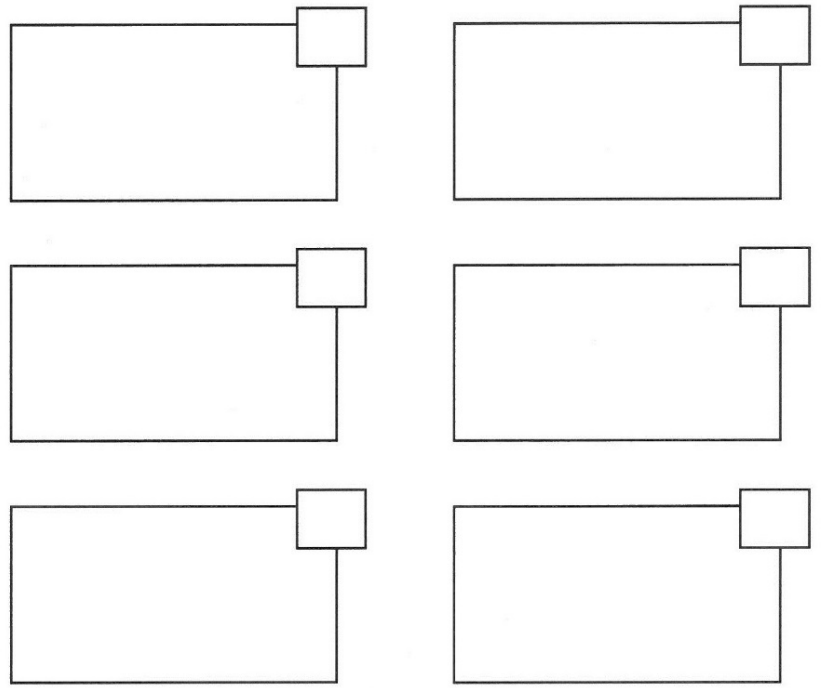

II. Now put each picture into a sentence or complete the following sentences.

To build my atom first I found the number of protons from the

Second I found the number of electrons from the . Next I found the number of neutrons

by $\_$my atom. I put $\quad$ green proton marbles in the $\_$Then I was ready to build
blue neutron marbles in the_. Next I put

Finally I put___ yellow electrons in the first energy level and ___ electrons in the second energy level.

III. To build my atom first I

Figure 1. Atom Worksheet

Throughout the class, Emerson, Guillermo, and Diwa were working very well together. Each of the three group members constructed their atoms, wrote their procedural paragraph, and then shared them aloud in their small group. Because there was a bit of time left before the bell rang to dismiss students to lunch, some students were able to read their work aloud to the whole class. The two effusive boys, Emerson and Guillermo, stood up and shared, but Diwa, who sat between them, chose not to. Instead, she continued to work on and revise her paragraph. At this point, Emerson was helping Diwa to put the final touches on her writing, and put his hand on her far shoulder to tap it and say "good job," as he acknowledged that the task was rather challenging for her. However, this gesture brought his face close to hers and she immediately threw his arm away. Her brother saw this from across the room and was very upset. Mohammed jumped up in anger, and with a red face hurled a punch at Emerson. Emerson, taken by surprise, naturally defended himself and hit back. Then Guillermo sprang up to restrain Mohammed's flailing arms, and another boy did the same for Emerson. Since the bell had just rung, the other classroom students were preparing to leave, but there was complete chaos in the room so no one could exit. Mohammed was red-faced, spitting, kicking and extremely worked up. Emerson was also very agitated and angry, but seemed dumbfounded, as though he was completely in the dark regarding why he was accosted.

While this was happening, other students were passing by Ms. Mayor's class and were trying to come in to the classroom to participate in the fight. Some Latinos were interested in helping Emerson, while some Muslim 
students professed their allegiance for Mohammed. All the while, Mohammed was hurling classroom objects-including a binder-- at his teacher's head. He also broke his wayfarer-style sunglasses, which splintered into pieces and bounced throughout the classroom. While Ms. Mayor encouraged the other students to exit the classroom, she also had to fend off the supporters of the fighters, and ultimately sustained some minor injuries in so doing.

Within minutes, the school principal came to break up the fight and take the offenders to the office. The police had also been called, so the two boys were to be punished appropriately. However, at this point, no one was really clear as to why the fight occurred because they had not seen what happened between Diwa and Emerson. It was not until later in the school day that Ms. Mayor learned of the reason behind the incident.

\section{Analysis \& Discussion}

As mentioned, the teachers at the NSA receive regular training in culturally responsive teaching, as well as specific training in the backgrounds of the students in their classes, like the Syrian students Mohammed and Diwa, and the Central Americans, Emerson and Guillermo. But the fight still happened. With a school situation where teachers are indeed globally-minded, empathetic, and well-trained, it is important to ask why the altercation occurred. One piece of the puzzle was due to Mohammed's background. Mohammed's lack of language skills, in concert with the cultural issues intertwined with the siblings' relationship, played an important role in why the fight happened. In many cultures, females are very modest and conservative. They not only wear conservative dress, but also adhere to traditional values. In their native country, Diwa and Mohammed would likely have been separated in school, as females are often segregated from males at secondary grades (Al Hessan, 2016). In contrast, Emerson came from a very different society where males and females are not separated, and interact much like they do in American schools.

However, while Ms. Mayor knew that her students came from different cultural backgrounds, she did not anticipate that such differences could result in inflamed conflict during class time. What happened in the class was a seemingly innocent misunderstanding, but one that had serious implications. It was clear that Emerson was unaware of the fact that he had offended Diwa, much less her brother, Mohammed. Had he known that he should keep sufficient distance from Diwa, Emerson would likely have done so. In his eyes, Emerson was simply acknowledging his peer's work when he was praising Diwa. He did not understand that he was causing familial or cultural problems for her. The takeaway from this situation is that it is necessary to also teach students to work together, in addition to the teachers, so that the students can interact and collaborate appropriately and effectively in school. Additionally, teachers in schools with superdiverse classrooms must be constantly vigilant to the ever-changing demographics in their classes.

\section{Implications}

Diverse classrooms are the norm, not the exception. While many classrooms may not include the intense diversity of that in Ms. Mayor's class, they will likely have similar issues. Most mainstream classes do include at least a handful of cultural and linguistic background students whose needs must be addressed. In order to most appropriately meet those needs, it is vitally important to include diversity training for teachers of these students as well as the students themselves, and ensure this training goes hand in hand with the arrival of students from cultural groups new to the classroom. Direct efforts to create culturally responsive classrooms will reduce the amount of alienation newcomer immigrant students experience on a general basis (Heath, 1983). In this way, cultural clashes can be avoided, and diversity can be fostered. Potential ideas to address growing diversity in classrooms include the following:

\subsection{Meet and Greet Sessions}

Encourage the process of formally introducing new immigrant students to the class and invite them to speak about their country and culture. Create opportunities to develop and attend meet and greet sessions/discussion every time a new immigrant student joins the classroom.

\subsection{Cultural Information Exchange}

Create learning opportunities that can serve as mutual learning opportunities for both teachers and students. Growing diversity within public schools of the United States indicate a need for information sessions about different cultures and countries from which all the class students come.

\subsection{Educational Leadership Initiatives}

Reflective discussions with staff and faculty about designing and empowering culturally responsive classrooms should be integral components of school improvement strategies. School administrations must invest their efforts in creating sustainable initiatives that will increase engagement of CLD students in school programs. 


\subsection{Knowledge Banks at Schools}

Build 'knowledge banks' of case scenarios, solutions/outcomes for first-year teachers joining the workforce. This is a critical in-service resource that can immensely help new teachers. While extensive research support is available from the field of teacher education and training, knowledge banks located within libraries of public schools can serve the purpose of accessible learning resources that are readily available to the teachers who are new to the profession.

\subsection{Beyond Raising Awareness}

Raise awareness about foreign cultures from which new immigrant students hail in order to make the transition process less arduous for all the stakeholders. A detailed gathering of facts about particular cultures is key to preparing to teach and work with new students each year.

\subsection{Socialization}

Increase opportunities for new immigrant students to interact with their peers and understand the social culture of the school and community. This can potentially help dispel any misconceptions that may exist about a particular community of immigrants. Increased socialization can positively lead towards creation of better support systems for the new immigrant students in a foreign country.

\section{Conclusion}

It is important to utilize culturally responsive teaching methods in all classrooms, but it is critical to do so in classrooms characterized by superdiversity (Blommaert, 2013) such as that at the NSA. It is vitally important to not only provide training to teachers in culturally responsive education and knowledge regarding the specific cultures represented in our classes, but also to maintain and keep up such training. With growing number of immigrants in United States (and throughout the global community), it is important to revisit the configurations of students in today's classrooms and acknowledge the differences represented in the classes. Moreover, students, as well as teachers, should be given sufficient training to understand how to work in harmony in today's interactive and global classrooms. While traditional mainstream classes may not have the wide range of diversity as that in specialized newcomer schools, it is nevertheless important to be vigilant and proactive with regard to cultural awareness, understanding of students' backgrounds, and anticipation of potential conflicts. In this way, teachers and students can learn in and from each other in harmony, or at the very least, in a positive environment.

\section{References}

Al Hessan, M. (2016). Understanding the Syrian education system in a context of crisis. Vienna Institute of

Demography Working Paper, Austrian Academy of Sciences. Retrieved March 19, 2018 from

https://www.oeaw.ac.at/fileadmin/subsites/Institute/VID/PDF/Publications/Working_Papers/WP2016_09.p $\mathrm{df}$

Banks, J., \& Banks, C. (2009). Multicultural education: Issues and perspectives (7th ed.). Boston: John Wiley \& Sons. https://doi.org/10.1080/23770031.2009.11102861

Blommaert, J. (2013). Ethnography, superdiversity and linguistic landscapes. Bristol: Multilingual Matters.

Cazden, C. (2001). Classroom Discourse (2nd ed.) Portsmouth, NJ: Heinemann.

Chisholm, I. M. (1994). Preparing teachers for multicultural classrooms. Journal of Educational Issues of Language Minority Students, 14, 43-68.

DeCapua, A., \& Marshall, H. W. (2010). Students with limited or interrupted formal education in US classrooms. The Urban Review, 42(2), 159-173. https://doi.org/10.1007/s11256-009-0128-z

Diversity in the classroom. (2016, December 6). Retrieved November 29, 2017, from http://www.nytimes.com/interactive/projects/immigration/enrollment

Dovidio, J. F., Gaertner, S. L., Kawakami, K., \& Hodson, G. (2002). Why can't we just get along? Interpersonal biases and interracial distrust. Cultural Diversity and Ethnic Minority Psychology, 8(2), 88-102. https://doi.org/10.1037/1099-9809.8.2.88

Flores., S. M, Batalova., J, \& Fix., M. (2012). The Educational Trajectories of English Language Learners in Texas. Washington, DC: Migration Policy Institute.

Ford, D. (2010). Culturally responsive classrooms: Affirming culturally different gifted students. Gifted Child Today, 33(1), 50-53. https://doi.org/10.1177/107621751003300112 
Friedlander, M. (1991). The newcomer program: Helping immigrant students succeed in U.S. schools. NCBE Program Information Guide Series, 8, Retrieved from www.ncela.gwu.edu/pubs/pigs/pig8.htm

Gándara, P., \& Contreras, F. (2008). The Latino education crisis: The consequences of failed policies. Cambridge, MA: Harvard University Press.

Gay, G. (2010c). Culturally responsive teaching: Theory, research, and practice (2nd ed.). New York: Teachers College Press.

Gee, J. P. (2014). An Introduction to Discourse Analysis: Theory and Method, (4th ed.), London: Routledge.

Gay, G. (2010). Culturally Responsive Teaching: Theory, Research, \& Practice. New York: Teachers College Press.

Heath, S. B. (1983). Ways with words: Language, life and work in communities and classrooms. Cambridge, MA: Cambridge University Press.

Howard, T. C. (2010). Why race and culture matter in schools: Closing the achievement gap in America's classrooms. New York, NY: Teachers College Press.

Huff, R. E., Houskamp, B. M., Watkins, A. V., Stanton, M., \& Tavegia, B. (2005). The experiences of parents of gifted African American children: A phenomenological study. Roeper Review, 27(4), 215-221. https://doi.org/10.1080/02783190509554321

Institute of Education Statistics, National Center for Education Statistics. (2017). Racial/ethical enrollment in public schools. Retrieved from https://nces.ed.gov/programs/coe/indicator_cge.asp

Kea, C. D., Trent, S. C., \& Davis, C. P. (2002). African American student teachers' perceptions about preparedness to teach students from culturally and linguistically diverse backgrounds. Multiple Perspectives, 4(1), 18-25. https://doi.org/10.1207/S15327892MCP0401_4

Kuykendall, C. (2004). From rage to hope: Strategies for reclaiming black \& Hispanic students (2nd ed.). Bloomington, IN: National Education Service.

Moje, E. B., \& Hinchman, K. (2004). Culturally responsive practices for youth literacy learning. In T. L. Jetton, \& J. A. Dole (Eds.), Adolescent Literacy Research and Practice (pp. 321-350). New York: Guilford.

Office of English Language Acquisition (OELA) Fast Facts. (2017). Profiles of English Learners (ELs).

Pajares, F., \& Urdan, T. C. (2005). Educating Adolescents: Challenges and Strategies. North Carolina: Information Age Publishing.

Rychly, L., \& Graves, E. (2012). Teacher characteristics for culturally responsive pedagogy. Multicultural Perspectives, 14(1), 44-49. https://doi.org/10.1080/15210960.2012.646853

Sadker, D. M., Sadker, M. P., \& Zittleman, K. R. (2008). Teachers, schools, and society, annotated instructor's edition (8th ed.). Boston, MA: McGraw Hill.

Shade, B. J., Kelly, C., \& Oberg, M. (1997). Creating culturally responsive classrooms. Washington, DC. https://doi.org/10.1037/10268-000

Short, D. J., \& Boyson, B. A. (2012). Helping newcomer students succeed in secondary schools and beyond. Washington, DC, and McHenry, IL: Center for Applied Linguistics and Delta Systems.

Short, D. J. (1998). Secondary newcomer programs: Helping recent immigrants prepare for school success. Eric Digest (Report No. EDO - FL - 98 - 06). (ERIC Document Reproduction Service No. ED419385). Retrieved from ERIC database.

Snyder, T. D. (2007). Mini-digest of Education Statistics 2006 (NCES Publication No. 2007-067). Washington, DC: National Center for Education Statistics. Retrieved from http://nces.ed.gov/pubs2007/2007067.pdf

Villegas, A. M., \& Lucas, T. (2002). Preparing culturally responsive teachers: Rethinking the curriculum. Journal of Teacher Education, 53(1), 20-32. https://doi.org/10.1177/0022487102053001003

Watson-Gegeo, K. A. (1997). Classroom ethnography. In Encyclopedia of language and education (pp. 135-144). Springer, Dordrecht. https://doi.org/10.1007/978-94-011-4535-0_13

Whittaker, A., McDonald, M., \& Markowitz (2002, April). Learning together what we do not know: Preservice preparation for equity. Paper presented at the annual meeting of the American Educational Research Association, New Orleans, LA. 


\section{Notes}

Note 1 . The name of the school is a pseudonym.

Note 2. The name of the teacher is a pseudonym

Note 3 . All names of students in this study are pseudonyms.

\section{Copyrights}

Copyright for this article is retained by the author(s), with first publication rights granted to the journal.

This is an open-access article distributed under the terms and conditions of the Creative Commons Attribution license (http://creativecommons.org/licenses/by/4.0/). 